\title{
Talking about mental health from the most polluted city
}

\section{Opinion}

Disgust is a haunting emotion for the denizens of Kathmandu. So is anger. Irritation is their habit. They put on surgical mask to commute or move around the city. Kathmandu has been ranked one of the most polluted cities in the world; its air quality is almost lowest ${ }^{1}$ and pollution is a threat to public health. The causes of all pollutions are multifold. The main is the bad governance. Nepal, its country remained stifled by political bickering for centuries and economic instability owing to civil war that recently lasted for a decade. The attention was distracted from planned development as there was absence of elected leaders for two decades. The internal conflict chased the villagers to this very urbanized valley which environmentalists and experts are now naming 'dust bowl'. ${ }^{2}$ Dust and smog have reduced visibility on roads and hence drivers are at risk of serious accidents. Once a downpour befalls, all the sewage systems go astray. Last year a child died in the flood of sewage augmented by a heavy rainfall. ${ }^{3}$ The environmental problem is now cause of many collective and common illnesses including psychological disorders and respiratory diseases. The environmental changes, such as pollution, can induce stress, depression, anxiety and psychosis. ${ }^{4}$ Air pollution alone can cause cognition disorders, sick building syndrome, mood disorders, anxiety, interference in proper functioning of nervous system ${ }^{5}$ like delayed reaction times and lowered ability to concentrate ${ }^{6}$ and psychological distress. ${ }^{7}$ People in lower socioeconomic status are more exposed to vulnerable psychological conditions ${ }^{8}$ caused due to environmental pollution. There are few who can afford car and more who ride motorcycles and even more who walk. Car riders can at least close windows and therefore inhale less dusty air., ${ }^{9,10}$

In the city, the whole land is plastic-plastered; all water is sewagemixed; all air is dust-filled and smokey. Environmental health of Kathmandu is an ecological tragedy as arable lands are completely occupied by haphazard buildings. Integrated effort to revert Kathmandu's environmental fate is not felt yet. Where is hope of restoration to greenery and panorama once it was? Once Kathmandu was portrayed as the paradise city by an immigrant poet, the Aadikavi Bhanubhakta Acharya. It was less than two hundred years ago. Old name of this city was Kantipur, meaning city of luster. Now, the aesthetics is degraded as if it cannot be reverted ever. Perceptive pleasantry is gone and people are in lookout for parks or natural spots for holidaying in the periphery of city. The inhabitants of Kathmandu are forced to live in consistent fear of breathing in dirty air (including the vehicular emission and smoke of polythene), anxiety of contracting cancer and respiratory diseases like asthma, depression and despair. They have an escape mentality. If not for the economic reasons, many people would either return to village from where they emigrated or move to developed nations. Daily life has become so stressful, because they constantly fight with pollution in every step of life that they want to avoid this city. Guilt of having to stay in the polluted place is inside each person's head. Those who believe Kathmandu is their destiny are helpless. They are more worried about their children. Living in polluted metropolis is costlier because people
Volume 7 Issue 3 - 2018 Pralhad Adhikari
Department of Psychology and Philosophy, TriChandra Campus,
Nepal

Correspondence: Pralhad Adhikari, Professor, Department of Psychology and Philosophy, TriChandra Campus, Kathmandu, Nepal,Email pralhad.adhikari@gmail.com

Received: April 20, 2018| Published: May 08, 2018

have to buy surgical masks and drinkable water at inflated price every day. Increased cost again is a stressor in the capital of a poor nation.

Despite Kathmanduites apparently having psychologically adapted themselves to the downgrading environmental health, they sometimes are drawn attention to the deteriorating scenario and they become hopeless. It seems the government has acquired learned helplessness. Nonetheless, some cues are hope-arousing. Metropolis, with Traffic Department of Nepal Police, banned honking horn in the Kathmandu valley and surprisingly public complied. A campaign roughly named "Bagmati clean-up campaign" went on for hundreds of weeks to clean up a big and sacred river named Bagmati on the shore of which Kathmandu (previously called Nepal) was founded. The river was significantly cleansed off the plastic wastes and garbage . Fishes have restarted to be seen in the river. The implementation of new constitution is expected to decentralize power, resources and thus opportunities to various other cities of nation. This may lessen Kathmandu's population burden. Against the backdrop of gloomy picture and little efforts, the public themselves are the ones who should solve the problem. That's why, they have to focus on hopeful side even though it is bleak. Even an individual can make a difference by changing a few behaviors.

What can psychologists (or even sociologists) do? The psychologists can work with administrators to devise more effective ways to change behaviors of public. Since it is a matter of public health, inaction or idleness of a single segment of population including psychologists' will cost a lost. They can use the knowledge of social psychology to induce people to trash garbage in specified place and category, to use electric vehicles or public transport, not to burn polythene stuffs in the open, to comply with the environmental standards set by government, to plant trees, not to set up factories near residential areas, not to build houses just to let them for rent as an income source, and so on. Most importantly, the government is to be persuaded to be environment-friendly while framing the policies and rules. Government can create eco-friendly legal obligation and psychologists can work with government to make the public willingly act in ways that are helpful than detrimental to environment. For some problems like overcrowding, the government should have willpower to enforce strict decisions like banning construction of buildings for next twenty years in the central locations of city. Generation and 
use of hydropower should be the first priority in terms of energy. Moreover, public health scientists, environmental psychologists, health psychologists, social psychologists and sociologists need to collaborate on interdisciplinary researches more to find the ways to handle the mental health crisis as a public health issue and to change people's behaviors.

Kathmandu is the capital city of a Himalayan republic that has a lot of water resources. It is still the cultural capital of South Asia. If environment gets cleaned by correct endeavors, psychologically healthy society will not be the matter of imagination only. Maybe a self-actualized individual like the Buddha will emerge here again. Kathmandu has to and can return to its glory of paradise city but that will be achieved only if its government and habitants can work out enough towards ecosystem vitality.

\section{Acknowledgements}

None.

\section{Conflict of interest}

Authors declare that there is no conflict of interest.

\section{References}

1. Yale Center for Environmental Law \& Policy. (2018b). 2018;EPI Rankings.
2. Dixit NM. The dust bowl. Oped, The Kathmandu Post. 2017.

3. Concerns grow over 'death trap' roads of the capital. Republica. 2017.

4. Wiwanitkit V. Environmental Change and Psychological Impact. In: J Valentin, L Gamez, editors. Environmental Psychology: New Developments. p. 251-254. New York: Nova Science Publishers. 2010.

5. Lundberg A. Psychiatric aspects of air pollution. Otolaryngol Head Neck Surg. 1996;114(2):227-231.

6. Bullinger M. Psychological effects of air pollution on healthy residents-A time-series approach. 1989;9(2):103-118.

7. Eckart K. How air pollution clouds mental health. UW news. 2017.

8. Mackenbach JP. Socioeconomic inequalities in health in highincome countries: the facts and the options. In: L Steg, AEVD Berg, JIMD Groot, editors. Environmental Psychology: An Introduction. Chichester: BPS Blackwell. 2013.

9. Dhobi Khola. clean-up caps 200-week mark. Report. The Kathmandu Post. 2018.

10. Yale Center for Environmental Law \& Policy. 2018 Environmental Performance Index: Finds Air Quality As The Leading Environmental Threat To Public Health [Press release]. Yale News. 2018a. 